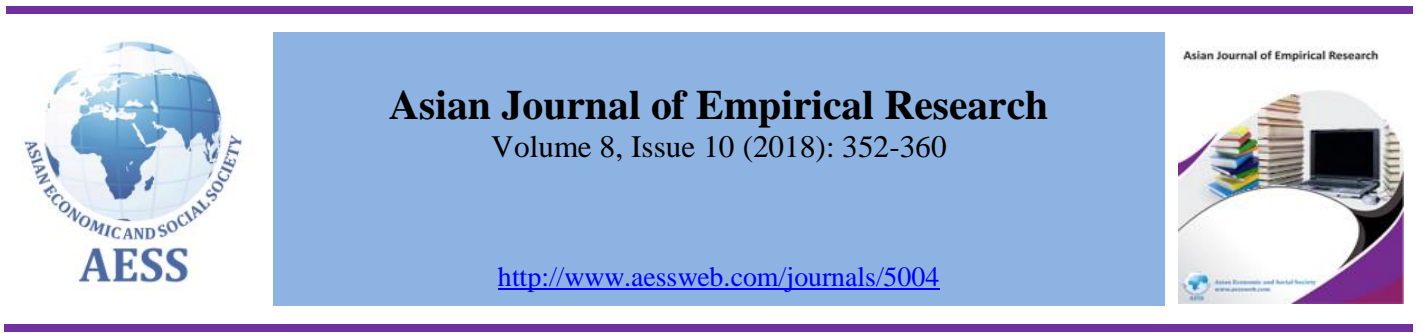

\title{
Effectiveness of E-learning for university students: evidence from Bangladesh
}

\author{
Mohammad Ali a $^{\text {a (D) S. M. Khaled Hossain }}$, (D) Tania \\ Ahmed $^{\mathrm{c}}$ \\ a Lecturer; Department of Management Studies, Bangladesh \\ University of Professionals, Bangladesh \\ ${ }^{\mathrm{b}}$ Lecturer; Department of Business Administration, City University, \\ Dhaka, Bangladesh \\ ${ }^{\mathrm{c}}$ Lecturer; Department of Management, Lalmatia Mohila College, \\ Dhaka, Bangladesh \\ \ rana.ali0191@gmail.com Corresponding author
}

\section{ARTICLE HISTORY:}

Received: 08-Oct-2018

Accepted: 08-Nov-2018

Online available: $26-\mathrm{Nov}-$

2018

\section{Keywords:}

E-learning,

Effectiveness,

Factor analysis,

University students

\begin{abstract}
The aim of current study is to analyse the effectiveness of elearning for the students at university level. Data have been collected through questionnaire and it was given to 700 students. The questionnaire was returned by 667 students and $94.9 \%$ of them are using different e-learning tools, techniques or platforms. Eight variables have been used to measure the effectiveness of elearning. Cronbach's alpha test is used to measure the reliability and internal consistency of the associated factors. The exploratory factor analysis is used to extract the variables and to measure the factors loading in the study. One sample t-test has been performed to test the hypotheses. The outcome of the study supports that elearning is faster, time and cost friendly, appropriate to work independently, add value to the learning of the students, usable for the purpose of active learning, faster, quick response, applicable outside the class room and quality of e-learning is satisfactory which indicates e-learning is effective.
\end{abstract}

\section{Contribution/ Originality}

The paper attempts to investigate the effectiveness of e-learning using some crucial and fundamental factors. The outcome of all the determinants endorses that e-learning is effective for university students. The study will contribute to encourage both students and academicians to grab the benefits of electronic tools, techniques and platforms by using it for the purposes of acquiring and sharing knowledge.

DOI: $10.18488 /$ journal.1007/2018.8.10/1007.10.352.360

ISSN (P): 2306-983X, ISSN (E): 2224-4425

How to cite: Mohammad Ali, S. M. Khaled Hossain and Tania Ahmed (2018). Effectiveness of Elearning for university students: evidence from Bangladesh. Asian Journal of Empirical Research, $8(10), 352-360$.

(C) 2018 Asian Economic and Social Society. All rights reserved 


\section{INTRODUCTION}

The use of e-learning is increasing day by day and it has become widespread in higher education. Elearning can give the opportunity to learn wherever and whenever they want, without the restrictions of an agenda. Learning is a process of acquiring knowledge and skills through study or other means for any specific purposes. The trend and way of learning has been changed over the years. Most of the students are likely to use mobile phones, tabs, laptops, notebooks and many other tools to acquire knowledge regarding academic and non-academic issues. Gradually, the traditional way of learning has been reduced and students are becoming more interested to learn quickly and easily by using technology. In today's world learning cannot be confined into traditional classroom and it may not require any physical presence (Zhang and Nunamaker, 2003). As the technology improved electronic learning is becoming significant for modern education. Technology should be used as the learning partner and the focus should be given on how people can learn as a result of the advancement of technology (Jonassen et al., 1999). Technology-driven learning system appeals to learners because of the convenience and learning is not limited by facilitators or teachers and time and distance cannot separate the learners (Raab et al., 2002). Computer is using as an important tool for elearning purposes. People can utilize diversified tools such as tablets, mobile phones apart from computers from anyplace. Users can also access the learning content from anywhere through multiple devices. Moreover, internet has become a great platform of e-learning. Different kinds of learning issues are rapidly accumulated, changed and updated over the internet. Especially for university students, e-learning can be a great source for acquiring knowledge and keep them updated in the knowledge-based world. A large number of factors can be used as the parameters to measure the effectiveness of e-learning. This paper used some crucial factors that can ensure the effectiveness of e-learning for the students at university level.

The advancement of technology has facilitated the learning process. A lot of students both undergraduate and graduate are using a wide array of e-learning tools and techniques for academic and non-academic learning purposes. But how far the e-learning is effective for the students? Many students can be misguided if they don't able to understand the effectiveness of the learning materials. It is required to scrutinize the extent to which e-learning is effective for the students at university level. This paper will be helpful for the students, instructors and practitioners to get an insight about the effectiveness of e-learning.

\section{LITERATURE REVIEW}

"E-learning" stands for "electronic learning". E-learning can be denoted as a mechanism of learning through electronic tools or techniques without using paper printed instructional material. It can be used for the purpose of both learning and teaching. E-learning can be defined as both online and offline learning engagements that are carried out by any individual or group (Naidu, 2006). Elearning can be viewed as a mechanism of obtaining knowledge through using a range of electronic media (Urdan and Weggen, 2000). In the narrow sense, e-learning can be defined as any learning activities which takes place over the Internet (Wang et al., 2007). In this paper, e-learning is defined as a technique through which individuals can learn by using a wide variety of tools (personal computer, notebook, mobile, laptop, tablet etc.) in different platforms (google, face book, online library, google scholars, twitter, e-mail, wikipedia, you-tube). E-learning is the use of information, communication and internet technologies for the purposes of enriching knowledge to ensure better performance. E-learning provides the opportunities to learn via computers and other electronic devices using technology that will help to improve the performance of individual, group and organization (Pollard and Hillage, 2001). So, e-learning is an electronic based learning process which can be used through electronic media by the learners and obviously they can learn with or without access over the internet.

E-learning is becoming a popular medium of learning as the number of internet users are increasing day by day (Goyal, 2012). Stability, security, reliability and responsiveness, ease of use, user- 
friendliness, organization, and personalization are the parameters to measure the effectiveness of elearning (Tseng et al., 2011). Gamage et al. (2014) used ten factors to analyze e-learning effectiveness and they ranked the top five which are interactivity, collaboration, motivation, network of opportunities and pedagogy. The experiment conducted by Zhang et al. (2006) showed that the effectiveness of e-learning through video depends on the provision of interactivity. Another study found that the e-learning effectiveness is highly interlinked with interactive learning activities, multimedia instruction and the quality of e-learning (Liaw, 2008). Wang (2003) developed a model in his study which contains four factors affecting e-learning and these are learner interface, learning community, content, and personalization. We used eight determinants to measure the e-learning effectiveness including contents of learning issues, usability of the information, faster learning, quick responsiveness, learning quality, time and cost friendly, usability outside of the class and appropriateness for working independently. Islam et al. (2010) found that variables such as reaction and satisfaction, learning outcome and achievement, and familiarity with online learning technology significantly affect the effectiveness of e-learning but it is not supported for participation and interaction. The findings of the study performed by Tseng et al. (2011) endorsed that the quality of the e-learning system and learner attractiveness are the most significant measures of e-learning effectiveness. Furthermore, reducing the waiting time and responsiveness of instructor's response to learner's question can improve the learning quality which lead to e-learning effectiveness. The study conducted by Salter et al. (2014) to determine the e-learning effectiveness on pharmacy education found that e-learning effectively contribute to increase the knowledge of pharmacist and pharmacy students but no evidence for long term perspective of knowledge. But the study could not conclude that whether e-learning can effectively improve skills or professional practice. On the other hand, it was found from the study of Noesgaard and Orngreen (2015) that it is tough to ensure e-learning effectiveness to improve the enactment of teaching since a teacher can apply various strategies as required.

The outcome of the study of Goyal (2012) reveals that e-learning is time and cost effective and it can be easily used and updated to meet the learning requirements. Furthermore, e-learning provides the freedom of learning which is interactive and entertaining. E-learning can be more effective than traditional classroom learning for students which will provide them updated knowledge to achieve the goals (Johnson et al., 2000). The similar outcome supported by the study of Rosenberg et al. (2003) and he added it is at least as effective as traditional instructional methods. E-learning significantly reduces the cost of learning, contributes to improve learning quality, and increases the access to education as well as training (Gilbert et al., 2007). Welsh et al., (2003) found that elearning ensures saving and he suggested e-learning as a potential replacement of classroom learning. E-learning is comparatively less expensive than learning through traditional class room (Strother, 2002). E-learning is a learner cantered that facilitate to acquire skills by wide range of ways including image, video, text etc. Unwin (2008) conducted a survey on e-learning in Africa and the study showed that most of the respondents remarked that e-learning is valuable and crucial to meet their learning and teaching needs. E-learning saves the learner's time and the learners can learn at their convenient time. Moreover, learning quality can also be better if learner can use the learning contents wisely. E-learning facilitates learners to take the control over the content, manage the learning sequences, determine the pace of learning, fix time and choose media to meet their learning objectives as well as to manage access to e-learning methods and materials (Jethro et al., 2012).

\subsection{Development of hypotheses}

$\mathrm{H}_{\mathrm{A} 1}$ : The content structure of e-learning is effective for the students.

$\mathrm{H}_{\mathrm{A} 2}$ : E-learning is effective for the purpose of active learning.

$\mathrm{H}_{\mathrm{A} 3}$ : E-learning is effective to learn faster.

$\mathrm{H}_{\mathrm{A} 4}$ : E-learning is effective to get quick response.

$\mathrm{H}_{\mathrm{A} 5}$ : The quality of e-learning is good.

$\mathrm{H}_{\mathrm{A} 6}$ : E-learning is time and cost friendly.

$\mathrm{H}_{\mathrm{A}}$ : E-learning is effective to apply outside of the class room.

$\mathrm{H}_{\mathrm{A} 8}$ : E-learning is effective to work independently. 


\section{RESEARCH FRAMEWORK}

In the study, the data were collected from the students of different backgrounds. Questionnaire was sent to 700 students, received from 667 and the response rate is almost 95\%. The study covers 6 public universities and 34 private universities in Bangladesh to collect data from the students. A structured questionnaire is used as the data collection instrument. Most of the statements of the questionnaire have been taken from the study of Song (2010). In the first part of the questionnaire contains 5- point Likert scale and fixed alternative questions and the second part includes the questions regarding the demographic state of the respondents. Eight variables are used to measure the effectiveness of e-learning including contents structure, usability, faster learning, quick responsiveness, learning quality, time and cost friendly, usability outside of the class and appropriate for working independently. Cronbach's Alpha test is used to test the reliability of the data. Frequency distribution and the percentage have been shown to analyse demographic state of the respondents. Factor analysis has been performed to measure the factors loading. To prove the hypotheses developed in the study, one sample t-test has been performed. SPSS 20.0 has been used to analyse all the data.

\section{Table 1: Demographic characteristics of respondents}

\begin{tabular}{lcc}
\hline & Frequency & Percentage \\
\hline Gender & 420 & \\
Male & 247 & 63.0 \\
Female & 667 & 37.0 \\
Total & & 100.0 \\
Education & 497 & \\
Graduation & 155 & 74.5 \\
Post-Graduation & 15 & 23.2 \\
Above post-graduation & 667 & 2.2 \\
Total & & 100.0 \\
Weekly Use of E-learning & 35 & \\
Missing value & 146 & 5.2 \\
1-2 days & 164 & 21.9 \\
3-4 days & 74 & 24.6 \\
5- 6 days & 248 & 11.1 \\
Everyday & 667 & 37.2 \\
Total & & 100.0 \\
\hline
\end{tabular}

\section{FINDINGS AND DISCUSSION}

The study found that among the 667 students $94.9 \%$ is using different e-learning tools, techniques or platform for academic learning or any other learning purposes. Students were asked that weekly how many days you like to use e-learning as a learning mechanism. The outcome of this statement reveals that most of the students use e-learning at least one day in a week and $37.2 \%$ percent students are using e-learning every day in a week.

\subsection{Reliability test}

We have used Cronbach's alpha test to evaluate the reliability of the factors and to understand how far they are internally consistent. The outcome of the test can be seen from table 2 and it shows that the coefficients ranged from 0.667 to 0.519 , indicating that factors are considered to be internally consistent. The values of all the factors are higher than 0.50 except for the factor-06 (Time and Cost friendly) which indicates there is a strong association and correlation among the factors used in the study. 
Table 2: Reliability statistics

\begin{tabular}{lcc}
\hline Factor's Name & Cronbach's Alpha & No of Items \\
\hline Factor-01: Contents Structure & 0.578 & 3 \\
Factor-02: Usability & 0.655 & 4 \\
Factor-03: Faster Learning & 0.589 & 3 \\
Factor-04: Quick Responsiveness & 0.595 & 2 \\
Factor-05: Learning Quality & 0.519 & 3 \\
Factor-06: Time and Cost Friendly & 0.370 & 3 \\
Factor-07: Usability of the outside of the class & 0.581 & 3 \\
Factor-08: Appropriate for Working Independently & 0.667 & 3 \\
\hline
\end{tabular}

\subsection{Factor analysis}

An exploratory factor analysis has been performed to identify the underlying relationships among the variables which have been used to measure the effectiveness of e-learning in learning process of university students of Bangladesh.

Table 3: KMO and Bartlett's test

\begin{tabular}{lcc}
\hline \multicolumn{2}{l}{ Kaiser-Meyer-Olkin Measure of Sampling Adequacy. } & 0.860 \\
& Approx. Chi-Square & 2920.530 \\
Bartlett's Test of Sphericity & df & 276 \\
& Sig. & 0.000 \\
\hline
\end{tabular}

The findings demonstrate that Bartlett's test of sphericity (with a value of $\chi 2=2920.530, \mathrm{df}=276, \mathrm{p}$ $<.001)$ and Kaiser Meyer-Olkin statistic calculated as 0.860 , which denotes that the data used for this research appropriate for factor analysis. To evaluate the factor dimensions, we have used principal component and varimax rotation. Principal component factors with eigen values of 1.0 or greater has been rotated by the varimax analysis. A total of 24 items from the factor analysis results in seven factor groupings and has explained $52.839 \%$ of the variance. The factors loadings are greater than 0.41 for all the factors which endorses that there is a good association between the items and the factor groupings to which they belong. The outcomes of the factor analysis are shown in table 04.

Table 4: Rotated component matrix ${ }^{a}$

\begin{tabular}{lccccccc} 
& $\mathbf{1}$ & $\mathbf{2}$ & $\mathbf{3}$ & $\begin{array}{c}\text { Component } \\
\mathbf{4}\end{array}$ & $\mathbf{5}$ & $\mathbf{6}$ & $\mathbf{7}$ \\
\hline CS-1 & 0.612 & & & & & \\
CS-2 & 0.642 & & & & & \\
CS-3 & 0.581 & & & & & \\
U-1 & 0.456 & & & & & \\
U-2 & 0.411 & & & & & \\
U-3 & & & & & & \\
U-4 & 0.595 & & & & & \\
FL-1 & & 0.712 & & & & \\
FL-2 & & 0.701 & & & & \\
FL-3 & & 0.554 & & & & \\
QR-1 & & 0.302 & & & & \\
QR-2 & & 0.571 & & & & \\
LQ-1 & & 0.452 & & & & & \\
LQ-2 & 0.358 & & & & & \\
LQ-3 & & & 0.564 & & & \\
TCF-1 & & & 0.684 & & & \\
TCF-2 & & & & & & \\
\hline
\end{tabular}




\begin{tabular}{|c|c|c|c|}
\hline TCF-3 & & & 0.734 \\
\hline UOC-1 & 0.765 & & \\
\hline UOC-2 & 0.686 & & \\
\hline UOC-3 & 0.485 & & \\
\hline AWI-1 & & 0.563 & \\
\hline AWI-2 & & 0.649 & \\
\hline AWI-3 & & & \\
\hline
\end{tabular}

The factors of the study include contents structure (factor 1), faster learning (factor 2), time and cost friendly (factor 3), usability of the outside of the class (factor 4), appropriate for working independently (factor 5), usability (factor 6) and learning quality (factor 7). The variance for contents structure $22.24 \%$, faster learning $6.905 \%$, time and cost friendly $5.528 \%$, usability outside of the class $5.163 \%$, appropriate for working independently $4.478 \%$, usability $4.357 \%$, learning quality $4.469 \%$. The above table of exploratory factor analysis shows that all the factors used in the study are highly loaded except learning quality.

\subsection{Descriptive statistics and hypotheses testing}

The researchers developed eight hypotheses to measure the effectiveness of e-learning for the students at university level. The result shows that the degree of freedom is 653 . The outcome of the test of hypotheses is presented in table 5 .

Table 5: Test of hypothesis

\begin{tabular}{lcccc}
\hline & t & df & Mean & Sig. (2-tailed) \\
\hline Contents Structure (CS) & 26.79 & 653 & 3.70 & 0.000 \\
Usability (U) & 17.94 & 653 & 3.64 & 0.000 \\
Faster learning (FT) & 14.82 & 653 & 3.44 & 0.000 \\
Quick Responsiveness (QR) & 13.84 & 653 & 3.47 & 0.000 \\
Learning Quality (LQ) & 27.74 & 653 & 3.73 & 0.000 \\
Time and Cost Friendly (TCF) & 25.40 & 653 & 3.87 & 0.000 \\
Usability of the outside of the class (UOC) & 25.87 & 653 & 3.73 & 0.000 \\
Appropriate for Working Independently (AWI) & 21.92 & 653 & 4.68 & 0.000 \\
\hline
\end{tabular}

The above table shows that for one sample t-test at 5\% significant level and at $95 \%$ confidence level the p-value [Sig. (2-tailed)] for content structure (CS) is .000 $(p<.05)$ which supports the hypothesis $\mathrm{H}_{\mathrm{A} 1}$ and approves the content structure of e-learning is worthy to add value to the learning of the students. The $\mathrm{p}$ value for usability (U) is smaller than .05 which approves that e-learning is usable for the purpose of active learning. Hypothesis $\mathrm{H}_{\mathrm{A} 3}$ has also been proved because the $\mathrm{p}$ value for faster learning (FT) is below than .05 which supports that the e-learning is effective for faster learning. For the variable quick responsiveness $(\mathrm{QR}) \mathrm{p}$ value is less than .05 which supports the hypothesis $\mathrm{H}_{\mathrm{A} 4}$ (e-learning is effective to get quick response). The outcome of t-taste for learning quality (LQ) is $p<.05$ and the $\mathrm{H}_{\mathrm{A} 5}$ has been proved which supports that the quality of e-learning is good. The $\mathrm{p}$ values for the variable time and cost friendly (TCF) is smaller than .05 which proved $\mathrm{H}_{6 \mathrm{~A}}$ and supports that e-learning is time and cost friendly. The $\mathrm{p}$ value for the outside of the class (UOC) is $p<.05$ which approved the hypothesis $\mathrm{H}_{\mathrm{A} 7}$ that e-learning is applicable outside the class room. Hypothesis $\mathrm{H}_{\mathrm{A} 8}$ has been proved by the outcome of $\mathrm{p}$ value which is lower than .05 and it supports that e-learning is appropriate to work independently (AWI). So, the hypotheses are statistically proved by not accepting the null hypothesis because the $p$ values of the variables are far below from .05 . The study shows that the mean of all the factors almost near to 4 which indicates most of the students agreed with the statement.

The outcome of the study reveals that almost $95 \%$ students are engaged with e-learning and they are aware of it. In overwhelming rate students are using different kinds of e-learning, tools, techniques and platform for the purposes of learning. Almost $94.8 \%$ of the students are using e-learning at least 
once in a week. There are eight hypotheses developed in the study and all of them are significantly accepted that indicates that e-learning is highly effective for the students. The outcome of the study discloses that the content structure of e-learning is worthy to add value to the learning of the students, it is usable, time and cost friendly, faster and applicable in the learning process. Except the variable learning quality, all the items in each factor are highly loaded which indicates that elearning is effective.

\section{CONCLUSION}

The study reveals that e-learning is effective for university students without regard to their background. But learning effectiveness may vary from students to students. The study highlights some variables to consider the effectiveness of e-learning. The existence of some variables virtually appear that e-learning is beneficial to some students and only for those variables e-learning may not be equally beneficial to others. The study considers some limited number of variables. Further research may be continued by covering a wide range of variables. The outcome of the study shows that students support e-learning is less time consuming, easy to use and cost friendly. It didn't show the extent to which e-learning is time and cost friendly. Another important issue is that the selfefficacy of students is also very important to get privileges from e-learning. The students having good knowledge about technology are abler to capture the benefits than those who don't have. But this paper did not consider this issue. More research can be conducted to analyse the impact of student's ability and their perception on the effectiveness use of e-learning.

\section{LIMITATIONS}

Though the researchers collected data from the students of different universities in Bangladesh, most of the universities are located in Dhaka City. Among the respondents, most of the students are from business background. The study didn't express the extent to which e-learning is effective for students. Furthermore, in this study researcher did not cover the learner's attitude, perception and motivation to determine the effectiveness of e-learning.

\section{Funding: This study received no specific financial support.}

Competing Interests: The authors declared that they have no conflict of interests.

Contributors/Acknowledgement: All authors participated equally in designing and estimation of current research.

Views and opinions expressed in this study are the views and opinions of the authors, Asian Journal of Empirical Research shall not be responsible or answerable for any loss, damage or liability etc. caused in relation to/arising out of the use of the content.

\section{References}

Gamage, D., Fernando, S., \& Perera, I. (2014). Factors affecting to effective eLearning: Learners Perspective. Scientific Research Journal (SCIRJ), 2(5), 42-48. view at Google scholar

Gilbert, J., Morton, S., \& Rowley, J. (2007). E-learning: The student experience. British Journal of Educational Technology, 38(4), 560-573. view at Google scholar

Goyal, S. (2012). E-Learning: future of education. Journal of Education and Learning, 6(2), 239242. view at Google scholar

Islam, A. M., Chittithaworn, C., Rozali, Z. A., \& Liang, H. (2010). Factors Affecting E-Learning Effectiveness in a Higher Learning Institution in Malaysia. Jurnal Pendidikan Malaysia, (Malaysian Journal of Education), 35(2), 51-60. view at Google scholar

Jethro, O. O., Grace, M. A., \& Thomas, K. A. (2012). E-learning and its effects on teaching and learning in a global age. International Journal of Academic Research in Business and Social Sciences, 2(1), 203-210. view at Google scholar

Johnson, S. D., Aragon, S. R., Shaik, N., \& Palma-Rivas, N. (2000). Comparative analysis of learner satisfaction and learning outcomes in online and face-to-face 
learning environments. Journal of Interactive Learning Research, 11(1), 29-49. view at Google scholar

Jonassen, D., Peck, K., \& Wilson, B. (1999). Learning with technology: a constructivist perspective. Prentice Hall, Inc. view at Google scholar

Liaw, S. S. (2008). Investigating students' perceived satisfaction, behavioral intention, and effectiveness of e-learning: A case study of the Blackboard system. Computers \& Education, 51(2), 864-873. view at Google scholar / view at publisher

Naidu, S. (2006). E-Learning: A guidebook of principles, procedures and practices. 2nd Revised Edition. New Delhi, India: Commonwealth Educational Media Center for Asia (CEMCA), and the Commonwealth of Learning. view at Google scholar

Noesgaard, S. S., \& Orngreen, R. (2015). The effectiveness of e-learning: an explorative and integrative review of the definitions, methodologies and factors that promote e-learning effectiveness. The Electronic Journal of e-Learning, 13(4), 278-290. view at Google scholar

Pollard, E., \& Hillage, J. (2001). Exploring e-learning. Brighton: Institute for Employment Studies. view at Google scholar

Raab, T. R., Ellis, W. W., \& Abdon, R. B. (2002). Multisectoral partnerships in e-learning: A potential force for improved human capital development in the Asia Pacific. Internet and Higher Education, 4(3), 217-229. view at Google scholar

Rosenberg, H., Grad, H. A., \& Matear, D. W. (2003). The effectiveness of computer-aid, selfinstructional programs in dental education: A systematic review of the literature. Journal of Dental Education, 67(4), 524-532. view at Google scholar

Salter, M. S., Pharm, B., Karia, A., Sanfilippo, M. F., \& Clifford, M. R. (2014). Effectiveness of elearning in pharmacy education. American Journal of Pharmaceutical Education 78(4), 1-12. view at Google scholar

Song, M. S. (2010). E-learning: Investigating students' acceptance of online learning in hospitality programs (Graduate Theses and Dissertations). Retrieved from https://lib.dr.iastate.edu/cgi/viewcontent.cgi?article=2917\&context=etd.

Strother, J. (2002). An assessment of the effectiveness of e-learning in corporate training programs. International Review of Research in Open and Distance Learning, 3(1), 1-17. view at Google scholar / view at publisher

Tseng, L. M., Lin, J. R., \& Chen, P. H. (2011). Evaluating the effectiveness of e-learning system in uncertainty. Industrial Management \& Data Systems, 111(6), 869-889. view at Google scholar

Unwin, T. (2008). Survey of e-learning in Africa. Royal Holloway University of London. view at Google scholar

Urdan, T. A., \& Weggen, C. C. (2000). Corporate e-learning: exploring a new frontier. W R Hambrecht and Co. view at Google scholar

Wang, S. Y. (2003). Assessment of learner satisfaction with asynchronous electronic learning systems. Information \& Management, 41(1), 75-86. view at Google scholar / view at publisher

Wang, S. Y., Wang, Y. H., \& Shee, Y. D. (2007). Measuring e-learning systems success in an organizational context: Scale development and validation. Computers in Human Behavior, 23(4), 1792-1808. view at Google scholar

Welsh, T. E., Wanberg, R. C., Brown, G. K., \& Simmering, J. M. (2003). E-learning: emerging uses, empirical results and future directions. International Journal of Training and Development, 7(4), 245-258. view at Google scholar / view at publisher

Zhang, D., \& Nunamaker, J. F. (2003). Powering e-Learning in the new millennium: An overview of e-Learning and enabling technology. Information Systems Frontiers, 5(2), 207-218. view at Google scholar

Zhang, D., Zhou, L., Briggs, R., \& Nunamaker, J. (2006). Instructional video in e-learning: Assessing the impact of interactive video on learning effectiveness. Information \& Management, 43(1), 15-27. view at Google scholar / view at publisher 


\section{Appendix}

Total variance explained

\begin{tabular}{|c|c|c|c|c|c|c|c|c|c|}
\hline \multirow{2}{*}{ Component } & \multicolumn{3}{|c|}{ Initial Eigen values } & \multicolumn{3}{|c|}{$\begin{array}{c}\text { Extraction sums of squared } \\
\text { loadings }\end{array}$} & \multicolumn{3}{|c|}{$\begin{array}{c}\text { Rotation sums of squared } \\
\text { loadings }\end{array}$} \\
\hline & Total & $\begin{array}{c}\% \text { of } \\
\text { Variance }\end{array}$ & $\begin{array}{c}\text { Cumulative } \\
\%\end{array}$ & Total & $\begin{array}{c}\% \text { of } \\
\text { Variance }\end{array}$ & $\begin{array}{c}\text { Cumulative } \\
\%\end{array}$ & Total & $\begin{array}{c}\% \text { of } \\
\text { Variance } \\
\end{array}$ & $\begin{array}{c}\text { Cumulative } \\
\%\end{array}$ \\
\hline 1 & 5.338 & 22.240 & 22.240 & 5.338 & 22.240 & 22.240 & 2.535 & 10.565 & 10.565 \\
\hline 2 & 1.657 & 6.905 & 29.145 & 1.657 & 6.905 & 29.145 & 2.354 & 9.807 & 20.372 \\
\hline 3 & 1.327 & 5.528 & 34.672 & 1.327 & 5.528 & 34.672 & 2.054 & 8.560 & 28.931 \\
\hline 4 & 1.239 & 5.163 & 39.836 & 1.239 & 5.163 & 39.836 & 1.771 & 7.381 & 36.312 \\
\hline 5 & 1.075 & 4.478 & 44.314 & 1.075 & 4.478 & 44.314 & 1.617 & 6.738 & 43.050 \\
\hline 6 & 1.046 & 4.357 & 48.671 & 1.046 & 4.357 & 48.671 & 1.228 & 5.115 & 48.165 \\
\hline 7 & 1.000 & 4.169 & 52.839 & 1.000 & 4.169 & 52.839 & 1.122 & 4.674 & 52.839 \\
\hline 8 & 0.945 & 3.936 & 56.775 & & & & & & \\
\hline 9 & 0.917 & 3.820 & 60.595 & & & & & & \\
\hline 10 & 0.907 & 3.777 & 64.372 & & & & & & \\
\hline 11 & 0.795 & 3.311 & 67.683 & & & & & & \\
\hline 12 & 0.784 & 3.265 & 70.948 & & & & & & \\
\hline 13 & 0.773 & 3.220 & 74.168 & & & & & & \\
\hline 14 & 0.752 & 3.135 & 77.303 & & & & & & \\
\hline 15 & 0.695 & 2.896 & 80.199 & & & & & & \\
\hline 16 & 0.632 & 2.633 & 82.832 & & & & & & \\
\hline 17 & 0.606 & 2.523 & 85.355 & & & & & & \\
\hline 18 & 0.576 & 2.401 & 87.756 & & & & & & \\
\hline 19 & 0.566 & 2.357 & 90.113 & & & & & & \\
\hline 20 & 0.536 & 2.232 & 92.345 & & & & & & \\
\hline 21 & 0.501 & 2.088 & 94.434 & & & & & & \\
\hline 22 & 0.484 & 2.016 & 96.450 & & & & & & \\
\hline 23 & 0.431 & 1.797 & 98.247 & & & & & & \\
\hline 24 & 0.421 & 1.753 & 100.000 & & & & & & \\
\hline Extraction M & Method: & Principal & Component $A$ & Analy & & & & & \\
\hline
\end{tabular}

